\title{
A construção do nacional \\ Ricardo Severo e a Campanha de Arte Tradicional no Brasil (1910-1930)
}

\section{The Construction of the National}

Ricardo Severo and the Campaign for Traditional Art in Brazil (1910-1930)

\author{
Joana Mello de Carvalho e Silva ${ }^{1}$ \\ http://orcid.org/0000-0001-5108-8186 \\ ${ }^{1}$ Faculdade de Arquitetura e Urbanismo \\ Universidade de São Paulo \\ Rua do Lago, 876, São Paulo, SP, 05.508-080, Brasil \\ joana-mello@usp.br
}

Resumo A Campanha de Arte Tradicional no Brasil, promovida por Ricardo Severo da Fonseca e Costa (1869-1940) entre as décadas de 1910 e 1930, foi composta por projetos de arquitetura; artigos e entrevistas publicadas em periódicos como O Estado de S. Paulo, a Revista do Brasil e A Cigarra, além de conferências proferidas em instituições como o Instituto Histórico e Geográfico de São Paulo, a Sociedade de Cultura Artística e o Grêmio Politécnico de São Paulo. Por meio dela, o engenheiro português construiu uma narrativa da história da arquitetura brasileira que foi pautada por e fomentou representações recorrentes da nação, reverberando nos escritos e nas políticas de preservação de intelectuais comprometidos com a criação de uma arte moderna genuína, entre eles José Marianno Filho, Mário de Andrade, Paulo Santos, Lucio Costa e Rodrigo Melo Franco de Andrade. Atento às especificidades do discurso de Severo, este artigo busca recuperar as motivações políticas e

Recebido: 31 jul. 2018 | Revisto pela autora em: 01 nov. 2018 | Aprovado em: 04 fev. 2019 http://dx.doi.org/10.1590/0104-87752019000200009

Varia Historia, Belo Horizonte, vol. 35, n. 68, p. 597-629, mai/ago 2019 
disciplinares de sua campanha; os nexos com sua experiência pregressa em Portugal, especialmente no campo da arqueologia; suas matrizes teóricas; suas fontes de pesquisa e seus veículos de divulgação, construindo pontes de diálogo entre o engenheiro português e seus contemporâneos. Palavras-chave Ricardo Severo, Campanha de Arte Tradicional no Brasil, historiografia

Abstract The Campaign for Traditional Art in Brazil, run by Ricardo Severo da Fonseca e Costa between the 1910s and 1930s, consisted of architectural projects, articles, and interviews published in periodicals such as O Estado de S. Paulo, Revista do Brasil and A Cigarra, as well as lectures held at institutions such as Instituto Histórico e Geográfico de São Paulo, Sociedade de Cultura Artística and Grêmio Politécnico de São Paulo. Through this campaign, the Portuguese engineer constructed a narrative of the history of Brazilian architecture that was based on and fostered recurrent representations of the nation, reverberating in the writings and preservation policies of intellectuals committed to the creation of a genuine modern art, such as Jose Marianno Filho, Mário de Andrade, Paulo Santos, Lucio Costa and Rodrigo Melo Franco de Andrade. Attentive to the specificities of Severo's discourse, this article seeks to uncover the political and disciplinary motivations of his campaign; its connection with his previous experience in Portugal, especially in the field of Archaeology; its theoretical matrices; research sources and means of dissemination, building bridges of dialogue between Severo and his contemporaries.

KeYwords Ricardo Severo, Campaign for Traditional Art in Brazil, historiography

\section{OS SENTIDOS DA ARQUITETURA: TESTEMUNHO E MEMÓRIA DE UMA NAÇÃO}

A Campanha de Arte Tradicional no Brasil foi promovida por Ricardo Severo da Fonseca e Costa (1869-1940) no entre-guerras em meio as comemorações do Centenário da Independência do Brasil e os debates 
nacionalistas que animaram o cenário artístico-cultural brasileiro e latino-americano entre as décadas de 1910 e 1930 (Amaral, 1994; Mello, 2007). Composta por projetos de arquitetura; artigos e entrevistas publicadas no jornal O Estado de S. Paulo, a Revista do Brasil e A Cigarra, além de conferências proferidas no Instituto Histórico e Geográfico de São Paulo (IHGSP), na Sociedade de Cultura Artística e no Grêmio Politécnico de São Paulo, sua promoção teve motivações diversas, mas entrelaçadas. Do interesse pelo período colonial face à destruição da herança portuguesa em curso desde o século XIX ao compromisso de recuperá-la para criar uma "estética de expressão nova", passando pelo envolvimento com a colônia portuguesa, o nó que, em grande medida, as atava era o apreço patriótico por Portugal. Se em sua terra natal, este compromisso se desenvolveu por meio da arqueologia, animado pelo projeto nacionalista republicano de redimir a pátria decaída em um momento de crise, inventando um passado mítico de extração evolucionista e racial (Hobsbawm, 1997), no Brasil ele teve outros desdobramentos.

Impedido de dar continuidade às suas pesquisas desde que se transferiu definitivamente do Porto para São Paulo entre 1907 e 1908, deixando para trás a sua realização preferida — a revista Portugália (1897-1908) —, Severo se voltou para a arquitetura. A mudança ocorreu não só porque a arqueologia não era uma disciplina constituída no Brasil, ou porque ele logo se associou ao arquiteto Francisco de Paula Ramos de Azevedo (1851-1928) (Lemos, 1993; Mello, 2007), mas porque a matéria lhe proporcionava tratar da nacionalidade portuguesa, destacando a sua importância na constituição da nação brasileira. Além disso, a pesquisa arquitetural lhe permitia responder ao ambiente nacionalista das primeiras décadas do século XX e a sua intenção persistente, pelo menos até os anos de 1930, de constituir um movimento associativo luso-brasileiro de largo alcance que valorasse o legado português e superasse o sentimento antilusitano que então prosperava (Rowald, 2000).

A escolha da arquitetura por Severo como expressão da nação, não era isolada, marcando os debates e o conjunto de iniciativas empreendido por diversos profissionais que se vincularam ao neocolonial e/ou à arquitetura 
moderna, ${ }^{1}$ como José Marianno Filho (1881-1946), Mário de Andrade (1893-1945), Lucio Costa (1902-1998), Paulo Santos (1904-1988) e Rodrigo Melo Franco de Andrade (1898-1969). Nesse período, eram frequentes as associações entre Estado e arquitetura, disciplina que não por acaso ganhou protagonismo nas políticas de preservação patrimonial (Gonçalves, 1996; Chuva, 2009). Nas palavras de Marianna Ramos Boghosian Al Assal,

De vocação eminentemente exibicionista por seu caráter de fruição coletiva, a arquitetura se relaciona com a invenção ou imaginação da identidade nacional em seu duplo e dialético sentido de criação de um passado legitimador relacionado particularmente à esfera da cultura, bem como de símbolos contemporâneos socialmente reconhecíveis e apropriáveis. Por um lado, coloca-se a dimensão da arquitetura enquanto herança do passado em sua dimensão documento-monumento (Le Goff, 2003), e por outro, seu caráter de construção simbólica do presente onde seu aspecto visual se referencia e propõe novas construções para o imaginário coletivo (Al Assal, 2014, p.23-24).

Essa dualidade de sentidos - presente também entre os adeptos da arquitetura moderna que, vinculados ao Estado varguista, construíram edifícios icônicos e estabeleceram uma narrativa historiográfica que informou a ação patrimonial (Cavalcanti, 2006; Chuva, 2009)

1 A tomada da arquitetura como um veículo de comunicação que participava da constituição e consolidação da nação define e aproxima as duas manifestações arquitetônicas, mesmo nas suas diferenças. Assim, embora utilize a terminologia neocolonial e moderno corrente na historiografia da arquitetura (MARTINS, 1987; AMARAL, 1994; CAVALCANTI, 2006; KESSEL, 2008; PINHEIRO, 2011) em função de sua consagração ao longo do tempo e das diferenças de princípios que ordenaram a sua prática projetual, estou atenta as disputas em torno do termo moderno protagonizadas pelos arquitetos no processo de constituição de seu campo profissional (CHUVA, 2009) e considero que ambas manifestações arquitetônicas são proposições formuladas diante dos desafios colocados pelo processo de modernização e das questões postas pela modernidade a partir do século XVIII, por isso passíveis de serem classificadas como modernas (BERMAN, 1986). Em virtude dessas ponderações os termos aparecem ao longo do texto em itálico. 
- é expressa por Severo na crença de que a "arte arquitetural, mais do que em outras [...] não se esconde - qualquer que seja o estilo e a época - a característica basilar de formação [da nação], indicando a sua mais longínqua proveniência”. ${ }^{2}$ Assim, por estar ligada "intimamente ao modo de ser dos povos desde as suas origens, aos seus primitivos usos e costumes", a arquitetura seria capaz de guardar e exprimir a "história evolutiva de um organismo social", "o cunho indelével da sua ascendência, o caráter dominante do seu ser moral”. ${ }^{3}$ Daí a pertinência de dar à sua investigação um cunho arqueológico, mesmo em se tratando de um país de recente formação. Afinal, para a arqueologia, "as mais rústicas ruínas têm um valor máximo e o mais modesto edifício têm uma brilhante significação, pela natureza dos seus materiais, técnica construtiva, caráter arquitetônico, época, estilo ou escola, seu destino e tradição". ${ }^{4}$

Era a partir desse critério etnográfico-arqueológico que Severo procurava superar por completo

falsas condenações de historiadores e estetas, cuja erudição se reporta aos tipos monumentais das grandes metrópoles (colecionados em livros ou rápidas viagens), das épocas mais brilhantes da sua civilização, modelos que muitas vezes se encontram deslocados no meio local e tradicional que os envolve, como criações de estranha suntuosidade, fulgurações de um gênero exótico, produzindo admiração e apreço, mas não o respeito e veneração do povo. ${ }^{5}$

A perspectiva denota não apenas o seu engajamento nacionalista, a valorização de sua formação e atuação pregressa em Portugal, mas também o impacto das descobertas arqueológicas sobre a cultura

2 SEVERO, Ricarådo. A Arte Tradicional no Brasil: a casa e o templo (1914). In: Sociedade de Cultura Artística. Conferências 1914-1915. São Paulo: Tipographia Levi, 1916. p.42.

3 SEVERO, Ricardo. A Arte Tradicional no Brasil: a casa e o templo (1914). p.43-44.

4 SEVERO, Ricardo. A Arte Tradicional no Brasil (1916). Revista do Brasil (São Paulo), ano II, vol. 4, p.394-424, jan.-abr. 1917. p.400. Disponível em: http://www.dezenovevinte.net/txt_ artistas/rsevero_atb.htm\#_ftn1. Acesso em 10 out. 2018.

5 SEVERO, Ricardo. A Arte Tradicional no Brasil (1916). p.401. 
arquitetônica desde os setecentos (Collins, 1973; Patetta, 1977; 1987). Um impacto que teve vários desdobramentos: um relativo ao sentido cultural que passou a se creditar à arquitetura e outro concernente ao agravamento da crise que se instalou no cerne do sistema clássico diante do descompasso entre o que se via e o que se conhecia do mundo antigo pelo filtro do Renascimento. A diversidade das manifestações arquitetônicas que então se descobria impulsionou revisões acerca da Antiguidade e a valorização de outros períodos e linguagens até então desprezados pelo campo erudito (Patetta, 1977; 1987; Collins, 1973; Azevedo, 2009), inclusive as mais simples como as do Brasil colonial que tanto interessavam ao engenheiro português.

No caso de Severo, esta valorização era pautada no horizonte artístico romântico de afirmação da imaginação e do sentimento como centrais na experiência de fruição da arte, para além da percepção racional e objetiva das obras. Ela estava calcada também na revisão da função que a beleza deveria desempenhar em arquitetura. Uma função que não deveria ser reduzida à excelência artística, à perfeita conformidade com normas ideias e abstratas para despertar múltiplas associações emocionais de caráter histórico, étnico e/ou religioso (Collins, 1973; Pinheiro, 2011). Apostava-se, assim, na capacidade comunicativa da arquitetura, cujo sentido poético e moral marcaria o debate e a produção arquitetônica a partir do século XVIII (Patetta, 1977; 1987; Colquhoun, 2006), com especial repercussão durante os oitocentos no contexto de afirmação dos Estados Nacionais e de definição de uma nova ordem mundial (Hobsbawm, 1992).

Essa aposta repercute entre adeptos do neocolonial, como Severo, e nas proposições de arquitetos modernos como Lucio Costa, ainda que a partir de parâmetros arquitetônicos racionalistas, distintos da lógica tipológica- estilística ${ }^{6}$ dos primeiros (Rocha-Peixoto, 2013). Atento a necessidade de definir a caracterização apropriada para cada edifício, conforme os ensinamentos de Antoine Chrysostôme Quatremère de Quincy (1755-1849)

6 Segundo esta lógica para cada edifício havia, conforme o uso, um estilo específico, consagrado ao longo do tempo, a ser escolhido para a sua construção. LASSANCE, 2009. 
(Comas, 2010a), Costa e os arquitetos que em torno dele gravitaram, procuravam atender "a arte de tornar sensíveis, pelas formas materiais, as qualidades intelectuais e as formas morais que podem ser expressas por meio da arquitetura, ou de tornar conhecidas a natureza, propriedade, uso e propósito de um edifício por meio da harmonia ou conveniência de suas partes constitutivas" (Comas, 2010b, p.63-64).

A definição desse caráter, contudo, não se dava para Lucio Costa a partir da recuperação direta de estilos pretéritos, mas da compreensão do presente como uma continuidade da evolução das relações entre forma arquitetônica e técnica construtiva (Banham, 1975; Rocha-Peixoto, 2013), a partir da qual seria possível criar obras pautadas por procedimentos autônomos e auto-reflexivos (Martins, 2010). A aproximação com o passado, nesse caso, apoiava-se na hipótese ensaiada por Auguste Choisy (1841-1909) e nas proposições das vanguardas modernas, dentro e fora do Brasil, de que "a boa arquitetura nova sempre se insere em harmonia com os conjuntos antigos se houver em ambas um comprometimento histórico com seu tempo respectivo" (Rocha-Peixoto, 2013, p.62), ou seja, se cada uma for a perfeita expressão do espírito do tempo, como demonstram claramente os argumentos desenvolvidos pelo arquiteto carioca em textos-manifestos como "Razões da Nova arquitetura" (1936) e "Documentação Necessária” (1937).

\section{OS SENTIDOS DA HISTÓRIA: A BUSCA DAS ORIGENS}

Voltando a Severo, a aproximação com a natureza, o elogio à irregularidade, ao local, ao característico, além da aposta na capacidade comunicativa da arquitetura, estão ao lado da perspectiva mesológica e racial, claramente presentes no discurso historicista do engenheiro português, como se nota em sua definição sobre a arte tradicional.

Arte tradicional é a estilização das formas artísticas anteriores que integram em determinado tempo e meio local, o caráter moral dum povo, o cunho da sua civilização; é o produto duma evolução rítmica de ciclos sucessivos de arte e estilos; é uma expressão coletiva, estranha à vontade 
individual, do pleno domínio do sentimento, determinada em povos de tradição definida, nos quais o sentimento estético é estável como o sentimento da nacionalidade pátria. ${ }^{7}$

A mudança de concepção da arquitetura aliada às motivações políticas já expressas, ajudam a compreender porque para Severo a arquitetura servia tanto à recuperação do momento de fundação de um determinado povo quanto ao culto patriótico, o mesmo ocorrendo entre os chamados modernos. Em sua narrativa historiográfica e atuação projetual, Severo tecia íntimas relações com "os temas que [permeavam] o debate em torno do nacional" (Guimarães, 1988, p.5), estabelecendo um compromisso com a "exaltação e glória da pátria" (Schwarcz, 1993, p.102). À semelhança de historiadores e arquitetos do período, Severo e aqueles que constituíram a trama da historiografia da arquitetura brasileira (Martins, 1987) e o "patrimônio nacional” (Chuva, 2009), a história era "o meio indispensável para forjar a nacionalidade" (Guimarães, 1988, p.14). Dessa forma, na pena do engenheiro, a história da arquitetura brasileira atrelava-se à narrativa da "epopeia" da empresa colonizadora portuguesa na América, a partir da qual recuperava o que considerava as características basilares da jovem nação brasileira.

Desde 1911, quando proferiu o discurso "Culto à Tradição" para assumir a cadeira de sócio efetivo do IHGSP, Severo se alistava ao esforço daquela agremiação de desenvolver estudos histórico-antropológicos sobre o povo brasileiro e a sua nação, devotando especial atenção ao período colonial - tema que movimentava também as pesquisas desenvolvidas pelo Instituto Histórico e Geográfico Brasileiro (IHGB), desde a sua fundação, em 1838 (Guimarães, 1988; Gomes Júnior, 1998). Tal empenho é reconhecido por sua integração ao corpo diretor do instituto e pelo convite que recebeu para inaugurar as Conferências Vicentinas, ciclo de debates organizado em comemoração ao IV Centenário da Fundação de S. Vicente (1932), do qual participaram nomes proeminentes da historiografia nacional, como Affonso d'Escragnole

7 SEVERO, Ricardo. A Arte Tradicional no Brasil (1916). p.424-425. 
Taunay (1876-1958). Ao lado desses historiadores, Severo ensaiava na conferência "Origens e fatos da expansão portuguesa no Brasil até 1530" explicações acerca da formação da nação, a partir de São Paulo, procurando valorizar o legado português ao revisar a narrativa corrente acerca dos descobrimentos e da colonização.

Vale pontuar que pelo menos do ponto de vista específico da arquitetura havia diferenças entre eles, uma vez que Taunay em seu livro A Missão Artística de 1816 (1912) procurou, "como bom herdeiro de ilustres membros da missão [...] realçar sua importância artística e civilizatória [...] à custa de reduzir a arte colonial à condição de nulidade" (Gomes Júnior, 1998, p.48). O historiador não estava sozinho nessa avaliação. Homens ligados ao IHGB e à Academia de Belas Artes, empenhados em colocar "o Brasil no circuito das artes do Ocidente", como Manuel Araújo Porto Alegre (1806-1879), Manuel Duarte Moreira de Azevedo (1832-1903), Luiz Gonzaga Duque Estrada (1863-1911), Manuel Querino (1851-1923) e Diogo de Vasconcellos (1843-1927), mesmo interessados pela produção do período colonial, procurando matizar seus julgamentos ao considerar a sua razão de ser no contexto local, não deixariam de apontar sobre ela aspectos negativos ou divisar certa indiferença (Gomes Júnior, 1998). ${ }^{8}$ Exemplo contundente desta atitude foi a reforma empreendida na sede do instituto pelo primeiro secretário do IHGB, Max Fleiuss (1868-1943), por volta de 1900. A reforma tinha como objetivo substituir o "horrendo casarão" - no caso o antigo Convento do Carmo, um edifício setecentista que desde 1849 abrigava o instituto - "por um edifício de agradável efeito arquitetônico", de inspiração clássica (Kessel, 2008, p.68). Atitudes semelhantes ocorreram contemporaneamente em outras cidades capitais, sobretudo a partir da proclamação da República, quando "o colonial, a taipa e a Monarquia eram identificados com o atraso e a dependência;

8 GOMES JÚNIOR, 1998, inclui entre esses autores Ernesto da Cunha de Araújo Vianna (1851-1920). O trabalho de KESSEL, 2008, aponta, contudo, que o engenheiro e arquiteto tinha uma atitude muito mais positiva em relação ao período colonial, ao barroco, do que os demais no período. 
e o ecletismo, o tijolo e a República, com o progresso, a civilização e a Independência" (Fabris, 1987; Costa; Schwarcz, 2000; Silva; Castro, 2015, p.28).

Nesse contexto, é possível compreender a preocupação expressa por Severo, ${ }^{9}$ na sede daquele instituto em São Paulo, com o desprezo que era devotado "à obra das gerações que por aqui passaram em outras eras, e pela destruição a que vejo condenadas muitas tradições e construções de outros tempos, cuja legenda ou cuja arquitetura são as mais comoventes recordações da vida dos vossos nobres antepassados". ${ }^{10}$ A mesma preocupação era expressa na conferência "A Arte Tradicional no Brasil" (1916) e por agentes como Marianno Filho, Mário de Andrade, Lúcio Costa, Paulo Santos e Rodrigo Melo Franco de Andrade, sempre para justificar a necessidade ética e estética de práticas de rememoração e preservação (Gonçalves, 1996; Chuva, 2009; Pinheiro, 2011). A despeito das diferenças, a motivação era a mesma: a construção e louvação, discursiva e material, de um passado original que definisse a nação, garantindo a sua coesão e caráter num momento marcado por intensas disputas político-econômicas que envolviam diversas manifestações culturais, incluindo a arquitetura.

Em ambos pronunciamentos, o engenheiro explicava que esta atitude de desprezo frente ao período colonial era motivada pelo argumento recorrente de que "foi de lamentável pequenez o povo criador, a raça decadente e inerte no seu conservantismo, a história um martirológio [sic] de opressão e revoltas, a civilização tacanha e de arte nula”. Sua

9 Vale apontar que outro membro do IHGB, nome importante para o debate acerca do patrimônio no Brasil, Gustavo Barroso, escreveu sob o pseudônimo de João no Norte, em 1912, o artigo "O culto da saudade", no qual expressava a mesma preocupação com 'o descaso pelas nossas tradições” (KESSEL, 2008, p.83). A concordância revela como nas primeiras décadas do século XX, apesar da atitude hegemônica de desprezo com relação ao período colonial, que incluía a arquitetura, as letras e outras formas de manifestação cultural e política, havia vozes dissonantes que proclamavam a sua importância para a constituição da nação. COSTA; SCHWARCZ, 2000.

10 SEVERO, Ricardo. Culto à Tradição (1911). In: Academia Paulista de Letras. Homenagem a Ricardo Severo: centenário do seu nascimento 1869-1969. São Paulo, SN, 1969. p.52. 
oposição a esta atitude e interpretação da história do Brasil não se restringia à narrativa, mas abarcava o método empregado por esses críticos, entre eles o historiador português da geração de 70, Joaquim Pedro de Oliveira Martins (1845-1894), cuja obra teria, segundo o engenheiro, repercutido com força no Brasil. Do seu ponto de vista, "conduzido por um critério racionalista, afastado do método de investigação direta — da análise etnográfica e arqueológica - Oliveira Martins não retratou com verdade os quadros históricos que descreveu, desvirtuando-os sob a lógica e uma ética que não se adaptam à natureza regional, à civilização da época, à religião e à moral do povo". O engenheiro continua dando pistas de seu paradigma historiográfico:

O mesmo raciocínio de imaginativo humanismo tem guiado os inovadores e revolucionários de todos os tempos, que se devotam a um tipo de homem ideal, o qual, de verdade não existe em nenhures; pelo contrário os naturalistas e tradicionalistas reportam-se ao homem real, com todas as suas características especiais, produto do meio presente, gerado pelo passado, donde provêm todos os elementos criadores da sua individualidade física e do seu caráter moral. ${ }^{11}$

Alinhado à atitude romântica e ao paradigma historicista, Severo criticava a perspectiva universalista do iluminismo em prol de uma visada particularizante, "seja valorizando a singularidade das localidades e povos específicos, seja ressaltando a singularidade de cada indivíduo" (Barros, 2014, p.81). Ao mesmo tempo, participando do processo de profissionalização da história, como um campo disciplinar específico, Severo defendia que todo o estudo deveria partir das evidências que pudessem ser extraídas "rigorosamente da documentação e de outros tipos de fontes" (Barros, 2014, p.15). A partir desse referencial, propunha traçar uma história "científica" e "verdadeira" dos descobrimentos e expedições portuguesas, procurando superar a falta de documentos

11 SEVERO, Ricardo. A Arte Tradicional no Brasil (1916). p.396. 
sobre o período e "a precariedade e mesmo falseamento dos estudos até então realizados sobre o tema". ${ }^{12}$

Divulgados na conferência vicentina de 1932, os resultados desses esforços se apoiariam em novas descobertas historiográficas e nos estudos desenvolvidos pelo engenheiro em sua terra natal sobre sua grei, divulgados na conferência "Origens da nacionalidade portuguesa" (1911), proferida no IHGSP, em evento promovido pelo Centro Republicano Português. Nesse conjunto de exposições, Severo intentou "ver se, em troca do ouro e das pedras preciosas que daqui levou a metrópole, topamos cristalizações da tradição, diamantinos reflexos da arte, essências espirituais da alma nacional, isto é, da alma brasileira". ${ }^{13}$

\section{A GÊNESE DA NAÇÃo: elos estilísticos entre Portugal e Brasil}

Desde as primeiras manifestações sobre o tema, Severo supervalorizava a ascendência lusitana em detrimento da contribuição de "indígenas", "negros" e outros povos imigrantes na construção da nacionalidade brasileira e de sua arquitetura. Se com relação aos indígenas, ponderava que, ao menos "do ponto de vista das artes menores e decorativas", as suas manifestações artísticas, "pelo seu caráter e simbolismo original, se prestam a novas expressões estéticas", decretava, porém, que estas não seriam, "tradicionais, se bem que caracteristicamente autóctones" e, portanto, tão "exóticas no meio da "família brasileira [...] como os bronzes e os bibelôs da China e da Índia". ${ }^{14}$ Com relação aos negros, suas referências não passaram de um breve comentário sobre a escravidão, no qual se opunha à ideia de que esta teria sido de uma "barbárie" e "crueldade" sem tamanho. Quanto aos imigrantes de outras nacionalidades, Severo os definia como "aventureiros" que não teriam

12 SEVERO, Ricardo. Origens e fatos da expansão portuguesa no Brasil até 1530. Revista do Instituto Histórico e Geográfico de São Paulo (São Paulo), n. 29, p.17-18, 1932.

13 SEVERO, Ricardo. A Arte Tradicional no Brasil (1916). p.406-407.

14 SEVERO, Ricardo. A Arte Tradicional no Brasil: a casa e o templo (1914). p.44-46. 
se fixado a terra com o intuito de "constituir uma nova nação, moldada na sua original matriz étnica". Desse modo, o povo brasileiro, sua arte e arquitetura tinham para o engenheiro a sua "origem no coração da Ibéria”, sendo fruto da unidade e coesão do povo português e de seu desenvolvimento no meio americano. ${ }^{15}$

Esta construção narrativa se pautava pelo compromisso de Severo tanto em redimir a herança portuguesa quanto em refutar uma percepção bastante consensual à época que imputava à mestiçagem a causa do atraso ou mesmo da inviabilidade do Brasil (Schwarcz, 1993; Mello, 2007). Ao filiar essencialmente a nacionalidade brasileira à portuguesa, o "caráter do país" e a "lógica tradicional da cultura" local à matriz latina, ${ }^{16}$ o engenheiro procurava construir pontes com a Europa, laços com o ideal civilizador iluminista, excluindo de seu projeto nacional eminentemente branco, indígenas e negros. Nesse sentido, a narrativa de Severo se afinava mais uma vez com a historiografia produzida pelo IHGSP e o IHGB no seu esforço de "produzir uma homogeneização da visão de Brasil no interior das elites brasileiras", dando conta, ao mesmo tempo, de traçar a "gênese da Nação brasileira" e de inseri-la "numa tradição de civilização e progresso" (Guimarães, 1988, p.6-8; Mello, 2007, p.91-92), ou seja, aproximando o ideal iluminista dos esforços românticos de valorização nacional.

O referencial racial e mesológico orienta também os modernos, embora diferenças importantes entre eles mereçam ser exploradas. Mário de Andrade e Lucio Costa creditaram à mestiçagem não só um valor positivo, como a originalidade da arquitetura brasileira, num diálogo com Gilberto Freyre (1900-1987) (Lira, 1996; Peixoto, 2000; Silva, 2004; Rubino, 2010; Pinheiro, 2011). ${ }^{17}$ Ao passo que Paulo Santos — arquiteto

15 SEVERO, Ricardo. A Arte Tradicional no Brasil: a casa e o templo (1914). p.49.

16 SEVERO, Ricardo. A Arte Tradicional no Brasil: a casa e o templo (1914). p.51.

17 ANDRADE, Mario de. A arte religiosa no Brasil - Triunfo Eucarístico de 1733. Revista do Brasil (São Paulo), n. 49, p.5-12, jan. 1920-a. ANDRADE, Mario de. A arte religiosa no Brasil - Arte cristã. Revista do Brasil (São Paulo), n. 50, p.95-103, fev. 1920-b. ANDRADE, Mario de. A arte religiosa no Brasil - A arte religiosa no Rio. Revista do Brasil (São Paulo), n. 52, p.298-293, abr. 1920-c. ANDRADE, Mario de. A arte religiosa no Brasil - Em Minas Gerais. 
que manteve relações mais estreitas com o IHBG - enfatizava a importância da matriz lusitana a partir do reconhecimento de "constantes de sensibilidade". ${ }^{18}$

É interessante notar, a despeito das diferenças, o fato de que na consolidação do projeto historiográfico e patrimonial desenvolvido pelos modernos sob a batuta de Lucio Costa há uma valorização do colonial, do jesuítico e das raízes portuguesas que serviu a ênfase na unidade. Essa ênfase, em detrimento de "qualquer feição plural da nação" como defendia Mário de Andrade (Chuva, 2009, p.207), procurou estabelecer a "identificação de uma arte brasileira que pudesse se enquadrar na classificação tradicional da história da arte no mundo ocidental" (Chuva, 2009, p.107). Assim, filiados a um racionalismo universalista que não desprezava as especificidades locais e comprometidos com um projeto de modernidade que se orientava por um ideal de civilização de matriz europeia, o que era narrado como histórico e definido como patrimônio, inclusive pelos modernos, deveria promover um "elo de integração do Brasil ao mundo civilizado, o que se processou por meio da identificação de valores universais na produção artística colonial herdada pela nação brasileira” (Chuva, 2009, p.32).

Esse elo também se firmou para a produção contemporânea pela afiliação à "entente latina", corporificada nas proposições vanguardistas de Le Corbusier (1887-1965) (Martins, 2004). Assim, além da associação entre arquitetura, memória e Estado Nacional, neocoloniais e modernos se aproximam na definição do ponto de ligação entre a sua produção arquitetônica presente, moderna, porque nova, e o passado original da nação no seu vínculo com as nações ditas civilizadas a partir da experiência colonial. A distância entre eles se dá em função de proposições arquitetônicas pautadas por parâmetros diversos, tipológicos-estilísticas para os primeiros, racionalistas para os segundos.

Revista do Brasil (São Paulo), n. 54, p.103-111, jul. 1920-d. COSTA, Lucio. Documentação necessária. In: XAVIER, Alberto (org.). Lúcio Costa: sôbre arquitetura [sic]. Porto Alegre: UniRitter Editora, 2007. p.86-94.

18 SANTOS, Paulo Ferreira. O Barroco e o Jesuítico na Arquitetura do Brasil. Rio de Janeiro: Kosmos Editora, 1951. 
Retomando mais uma vez o esforço de redenção da matriz lusitana de Severo. Os construtores da nacionalidade brasileira eram por ele retratados como homens, cujas origens remontavam à antiguidade e cuja contribuição para o desenvolvimento da humanidade se equiparava a dos gregos. ${ }^{19}$ A "firme coesão de caracteres étnicos", o "caráter aventureiro e heroico" dos portugueses teriam os talhado para cedo definir seu território, estabelecer sua organização política, dominar a ciência da navegação para construir um grande império atlântico conservando "a mesma virtude dominante de resistência à invasão destruidora de influências estrangeiras". ${ }^{20}$

Virtude esta confirmada pela arquitetura. Afinal, como procurava mostrar em suas conferências sobre o tema em Portugal, todos os estilos teriam tido, ao longo da história, uma feição particular que os diferenciavam das artes das outras nações. Assim, se no século XVI o "renascimento das artes do mundo clássico grego-romano [sic]" teria dominado o cenário artístico europeu, "vencendo as velhas artes medievais, que eram a expressão elevada da democracia cristã”, em Portugal esta arte de origem italiana, "aristocrática", de elevado "espírito de grandeza, de poder, e de domínio", porém "fria" e "hierática", teria encontrado resistência "de um estilo original, que havia adaptado as últimas labaredas do gótico flamejante à opulência dessa pequena monarquia", o Manuelino. ${ }^{21}$

Tal interpretação ecoava a leitura corrente que se fazia da história da arte/arquitetura em Portugal desde meados do século XIX, quando, segundo Paulo Pereira, o gótico, especialmente o tardo-gótico ou manuelino, passou a ser revalorizado como a primeira manifestação do estilo nacional e de resistência ao sentido universalista da arte renascentista (Pereira, 1999, p.336). Este movimento reabilitaria outro estilo fundamental para a narrativa historiográfica do engenheiro, o barroco

19 SEVERO, Ricardo. Culto à Tradição (1911). In: Academia Paulista de Letras. Homenagem a Ricardo Severo: centenário do seu nascimento 1869-1969. São Paulo, SN, 1969. p.51-52.

20 SEVERO, Ricardo. A Ciência Náutica Portuguesa e o Descobrimento do Brasil. São Paulo: Centro Republicano Português, 1931. p.49.

21 SEVERO, Ricardo. A Arte Tradicional no Brasil (1916). p.407. 
que seria "como o gótico, das mais belas expressões artísticas duma época e dum meio social" e, por isso, tinha "a legitimidade tão legal quanto o dogma clássico das ordens arquitetônicas dos panteões grego-romanos [sic]". Afinal, como um bom historicista, para Severo não havia na arte "estilos privilegiados", 22 "uma vez que cada estilo estaria organicamente relacionado a uma cultura espacial e temporalmente determinada, não podendo ser avaliado senão conforme os seus próprios termos" (Colquhoun, 2006, p.226).

Esta perspectiva que não se restringiu à Portugal, englobou outros países da Europa às Américas, incluindo o Brasil, marcando os debates entre o século XIX e a primeira metade do século XX. Nesse contexto, intelectuais de diversos países empreenderam buscas semelhantes pelas origens nacionais, gerando um conjunto amplo de revivalismos que se opunha ao sistema clássico e valorizava outras formas de manifestação arquitetônica (Patetta, 1977; 1987; Amaral, 1994; Meneguello, 2008; Atique, 2010). Severo estava, portanto, antenado com o debate de época, utilizando a palavra renascimento no mesmo sentido que a historiografia contemporânea dá ao termo revivalismo, ou seja, referindo-se à atitude de recuperar manifestações arquitetônicas pregressas como o objetivo de louvar o presente e o caráter da nação através da história.

De fato, entre os anos de 1895-97 e 1907-08, Severo envolveu-se com a campanha revivalista pela "casa portuguesa" que animou o renomado arquiteto português Raul Lino (1879-1974) e intelectuais nacionalistas da geração de 90 a qual pertencia (Backheuser, 2006). Nesse envolvimento, Severo aproveitou o conhecimento adquirido durante as expedições arqueológicas que realizara pelo país para construir, como um manifesto, sua residência particular no Porto. A obra ensejou um conjunto de artigos que, a despeito das críticas, reconheciam a sua importância por ter comprovado a viabilidade do movimento (Backheuser, 2006). A experiência sem dúvida preparou o engenheiro para a Campanha de Arte Tradicional no Brasil, pensada desde o início, e de modo declarado,

22 SEVERO, Ricardo. A Arte Tradicional no Brasil (1916). p.412. 
como uma continuidade das experiências pregressas em sua terra natal, tanto do ponto de vista discursivo, como projetual.

Voltando à análise da história da arquitetura empreendida por Severo. ${ }^{23}$ Do seu ponto de vista, se as origens do barroco remontavam à Itália, em Portugal a sua adaptação era tamanha que o estilo tinha se tornado a expressão da raça lusitana a partir do século XVII. ${ }^{24}$ Tal como ocorrera com o manuelino - cujo nome homenageava o reinado de D. Manuel -, o barroco era relacionado com outro momento de opulência econômica e política de Portugal, o reinado de D. João V. Severo aponta, contudo, que se o manuelino marcou o cenário metropolitano, o mesmo não teria ocorrido na colônia, pois o seu florescimento teria coincidido com o período inicial de colonização, quando não tinham se constituído exemplares de relevo. O barroco, por sua vez, teria sido transplantado para a colônia no momento de sua ocupação efetiva, aqui se adaptando ao meio e constituindo uma linguagem própria, derivada da metrópole. Por isso, Severo inicia sua narrativa acerca da história da arquitetura brasileira em meados do século XVII, destacando a produção realizada entre a metade do século XVIII e o início do XIX, período que concentraria o maior número de exemplares e de documentos que permitiriam o seu estudo científico.

23 Na conferência de 1916, procurando convencer o leitor do interesse e importância da arquitetura portuguesa do período, Severo - numa atitude que se assemelha a de intelectuais periféricos - afirma que "o valor da arte lusitana não é somente celebrado por escritores nacionais, mas também por sumidades do estrangeiro; poderia citar-vos os ingleses [James Cavanhah] Murphy [1760-181] e [Walter Crum] Watson, o polaco Conde [Atanazy] Raczynski (1788-1874), o italino Vasari, os alemães [Albrecht] Haupt [1852-1932] e C. Justi, os franceses [Marcel-Auguste] Dieulafoy [1844-1920] e Berteaux, os quais escreveram livros sobre essa arte originalmente portuguesa" SEVERO, Ricardo. A Arte Tradicional no Brasil (1916), p.419. É possível supor que estes tenham sido referências na pesquisa de Severo, mas isso ainda precisaria ser melhor averiguado. O que sabemos até o momento é que Albrecht Haupt desenvolveu um estudo bastante influente sobre a renascença portuguesa, marcando a formação de contemporâneos de Severo, entre eles Raul Lino. BACKHEUSER, 2006.

24 Na conferência de 1917, Severo apoia sua descrição e análise dos estilos arquitetônicos portugueses nas estampas VI, VII e VIII. Disponível em: http://www.dezenovevinte.net/txt_artistas/ rsevero_atb.htm\#_ftn1. Acesso em 26 jan. 2018. 


\section{Arquitetura tradicional No Brasil: CLASSIFICAÇÕES E CRONOLOGIA}

A intepretação de Severo frente à indiferença e/ou desqualificação da arquitetura do período colonial era nova no cenário brasileiro, tanto por avaliar positivamente aquela produção, em especial o barroco, quanto por tomá-la como um modelo-guia para os arquitetos contemporâneos. Era nova também a atenção devotada à tipologia habitacional, considerada pelo engenheiro "a nota normal da vida cotidiana do cidadão, [a] lápide epigráfica da sua ascendência e da sua história". ${ }^{25}$ Tal concepção, claramente apoiadas nas ideias expostas por John Ruskin no livro Sete lâmpadas da arquitetura (1849) (Pinheiro, 2011, p.39), o leva de modo pioneiro no Brasil a começar a sua narrativa pela habitação, para depois, em 1916, dedicar-se aos templos, edificações de maior porte que teriam marcado a sociedade colonial e suas cidades. ${ }^{26}$

Novamente aqui vale um paralelo com o discurso Lucio Costa. A valorização da casa orientou também a sua leitura em "Documentação Necessária”. Nesse artigo de tão longeva e duradoura influência, o arquiteto afirma que a "arquitetura popular apresenta em Portugal [...] interesse maior que a "erudita", porque é nela que "as qualidades da raça se mostram melhor". Apoiando-se em princípios raciais e mesológicos semelhantes aos do engenheiro português, Costa defende que estas qualidades se mantêm no Brasil, embora não se possa considerar a arquitetura popular aqui produzida apenas como expressão do povo lusitano em função da adaptação da arquitetura à "grandiosidade do cenário americano" e aos "costumes mais simples e [da] largueza maior da vida colonial" e de seu "amolecimento" pela contribuição do "índio" e do "negro".27

25 SEVERO, Ricardo. A Arte Tradicional no Brasil (1916), p.417.

26 As imagens que representam o que ele define como arquitetura doméstica tradicional compõe a Estampa IV que ilustrava a conferência A Arte Tradicional, proferida em 1917. Disponível em: http://www.dezenovevinte.net/txt_artistas/rsevero_atb.htm\#_ftn1. Acesso em 26 jan. 2018.

27 COSTA, Lucio. Lúcio Costa: sobre arquitetura. Porto Alegre: UniRitter Editora, 2007. p.86-87. 
Ecoavam na fala de Costa e de Severo, os preceitos da "estética naturalista" de Hippolyte Taine (1828-1893) para quem "o homem deveria ser compreendido à luz de três fatores essenciais: o meio ambiente, a raça [hereditariedade] e o 'momento histórico' [circunstância]" (Barros, 2014, p.100). No discurso do engenheiro português, essa referência teórica lastreava a afirmação de que a base sólida da arquitetura, aquilo que lhe garantia unidade desde o momento inicial de sua concepção até a contemporaneidade, era a etnia ou a raça, entendida como um conjunto de caracteres físicos e morais permanentes e homogêneos que eram transmitidos pelo sangue a cada nova geração. Embora a raça fosse o cerne da nacionalidade e de sua produção arquitetônica, a sua definição estaria incompleta sem considerar o meio natural no qual ela tinha sido gerada, pois uma mesma "matriz" podia dar "frutos" diversos a depender do "solo" onde fora "semeada". Da interação entre raça e meio nascia para Severo a tradição, que em suas palavras era "o esqueleto moral da nacionalidade, a base real do regime orgânico que deve manter o equilíbrio dos seus componentes sociais, a liberdade dos indivíduos, a integridade da nação". ${ }^{28}$ Nessa aproximação, o que distingue Severo de Costa é a afirmação da homogeneidade em contraponto ao elogio à mestiçagem, que aparece declaradamente no texto do arquiteto carioca a partir da interpretação de Gilberto Freyre de quem empresta o termo "amolecimento". O sistema de classificação das obras do período colonial também distinguia o engenheiro do arquiteto.

Em consonância com o "modo historicista" dominante na cultura arquitetônica acadêmica entre o século XIX e os primeiros decênios do século XX, Severo procedia à análise da arquitetura colonial procurando identificar e classificar, a maneira dos naturalistas, seus elementos característicos para, então, arranjá-los "em grupos e sub-grupos conforme os programas, os estilos, os tipos de composição [...] para fins de uso prático" (Rocha-Peixoto, 2013, p.36). ${ }^{29}$ Dessa forma, seguia os

28 SEVERO, Ricardo. Culto à Tradição (1911). p.52.

29 As estampas I, II e III ilustram os sub-grupos tal como definidos por Severo na conferência A Arte Tradicional no Brasil, proferida em 1917. Disponível em: http://www.dezenovevinte. net/txt_artistas/rsevero_atb.htm\#_ftn1. Acesso em 26 jan. 2018. 
ensinamentos acadêmicos de matriz francesa (Chafee, 1977; Backheuser, 2006), associando a "arquitetura analítica, encarregada de decompor a arquitetura histórica em seus elementos constitutivos e a composição de arquitetura que se incumbe de reagrupar os elementos identificados na análise em uma nova arquitetura" (Rocha-Peixoto, 2013, p.41-42). Aqui, a associação entre história e projeto, passado e presente, era regida pela lógica tipológico-estilística de maneira que o conhecimento do passado ordenado por sequências de estilos servia à legitimação da arquitetura contemporânea (Lassance, 2009). Costa, por sua vez, guiava-se pela perspectiva histórico-modernista (Rocha-Peixoto, 2013), ordenando as obras a partir de relações evolutivas entre técnicas construtivas e formas arquitetônicas. ${ }^{30}$

Era a partir desses preceitos naturalistas e historicistas, do esforço em estabelecer correspondências entre os exemplos locais e portugueses e da compreensão moderna da nação "como uma unidade objetiva, autônoma, dotada de nítidas fronteiras territoriais e culturais e de continuidade no tempo" (Gonçalves, 1988, p.266) que Severo classificava casas e templos do período colonial em "tipos arquitetônicos" ou "grupos arqueológicos," considerados paradigmáticos da tradição luso-brasileira, seja pela feição compositiva geral do edifício, seja por seu arranjo espacial ou detalhe ornamental. A seleção era realizada a partir dos modelos portugueses que aqui teriam alcançado melhor adaptação ou maior originalidade. Seu elogio se concentrava nos telhados de "quatro planos ou águas" de "largos beirais" e "bicas levantadas à moda chinesa"; na "gelosia ou rótula, chamada também adufa em Portugal, [...] sumariamente o modelo que os romanos empregaram com a designação de transenna, em tudo semelhante às addafas árabes e aos moucharabiehs do Cairo"; nos pátios centrais de fundo "romano-árabe; nos frontões, nas cornijas, nos pináculos e nos azulejos, cuja aplicação teria se generalizado em todo território colonial. ${ }^{31}$

30 COSTA, Lucio. Lúcio Costa: sobre arquitetura. p.91-93/ fig.3-15.

31 SEVERO, Ricardo. A Arte Tradicional no Brasil: a casa e o templo (1914). 
Para além dos aspectos formais, o engenheiro enfatizava a adaptabilidade desses elementos ao meio local. Por isso, destacava que o telhado tradicional "com o seu amplo beiral imita a copa das árvores frondosas, sombreando as fachadas, geralmente de pouco pé-direito, em uma atitude protetora e hospitaleira". ${ }^{32}$ A mesma analogia era retomada ao tratar da rótula, anteparo que, à semelhança das folhagens das árvores, coava a luz com o fim de garantir "sombra fresca e arejamento natural perfeito", "de resguardar a casa do sol, e para ver de dentro, sem ser visto de fora". 33

Esta interpretação ecoava a leitura de muitos viajantes estrangeiros, entre eles o inglês Henry Chamberlain (1796-1844) que, no livro Vista e costumes da cidade e arredores do Rio de Janeiro em 1819-1820, afirmava que as rótulas serviriam para acobertar visitas proibidas, inclusive amorosas, como retrata a sua famosa gravura "Uma história" (c. 1819-20). ${ }^{34}$ $\mathrm{O}$ artefato atenderia, então, à suposta "preservação do recato e ao resguardo do lar e do pudor a que estavam reduzidas as mulheres nas sociedades implantadas pela conquista" (Marins, 2001, p.32). Severo endossa essa leitura e, assim, contribui para perpetuar o mote do "ver sem ser visto", ou seja, a compreensão da rótula como um elemento de separação entre casas e ruas, de uma sociabilidade pautada pelo recato e pela reclusão, em tudo diversa da experiência social e dos sentidos que este elemento assumiu de fato durante o período colonial (Marins, 2001, p.262). Essa interpretação - repisada ao longo do século XX, inclusive entre trabalhos universitários - projeta "sobre a sociedade colonial questões anacrônicas suscitadas pela ascensão da burguesia" (Marins, 2001, p.12), que não deixam ver que a rótula não serviu a cisão, mas a união entre casa e rua, viabilizando "a comunicação e sociabilidade, sem que os espaços associados à condição senhorial fossem formalmente transpostos (Marins, 2001, p.33). Tal projeção se daria porque os discursos textual e narrativo de Chamberlain e Jean-Baptiste Debret

32 SEVERO, Ricardo. A Arte Tradicional no Brasil: a casa e o templo (1914). p.57.

33 SEVERO, Ricardo. A Arte Tradicional no Brasil: a casa e o templo (1914). p.61-62.

34 SEVERO, Ricardo. A Arte Tradicional no Brasil: a casa e o templo (1914). p.61-62; p.69-71; est. IV e V. 
(1768-1848), outra referência importante para Severo, foram tomados como um documento capaz de atestar a "verdade dos fatos, a realidade objetiva e a imparcialidade do autor", afinal seus relatos decorriam de uma "vivência, e suas ilustrações se originariam de desenhos tomados 'd'après nature", o que era considerado uma prova cabal de credibilidade (Silva, 2001, p.52).

Do ponto de vista da arquitetura residencial, Severo remontava às duas pranchas que Debret dedicou ao tema no terceiro volume - "Política e religião" - do livro Viagem pitoresca e histórica ao Brasil: "Plantas e elevações de duas pequenas casas brasileiras, de cidade e de campo"35 e "Plantas de duas grandes casas, de cidade e de campo". ${ }^{36}$ Endossando integralmente a interpretação do artista francês, Severo priorizou nesta análise a organização interna da habitação, reforçando a filiação lusitana dessas tipologias; "a sua perfeita adaptação às condições higiênicas principais que competem ao clima local” - à exceção das "alcovas sem luz direta; e o interesse pelo "plano da casa com o pátio central ou aberto para uma das fachadas", pelas mesmas qualidades de "melhor insolação e arejamento", já destacadas no caso dos telhados e rótulas. ${ }^{37}$

Debret foi recuperado pelo engenheiro também para atestar o valor da contribuição dos jesuítas, a quem o pintor francês atribuía a primazia na propagação da arquitetura portuguesa (Pinheiro, 2011). Essa valorização da contribuição jesuíta seria endossada por Mário de Andrade na série "A arte religiosa no Brasil", publicada na década de 1920 na Revista no Brasil (Andrade, 1920a-d; Pinheiro, 2011) e por Paulo Santos no livro O Barroco e o Jesuítico na Arquitetura Brasileira (1951), no qual, comentando a bibliografia sobre o tema, destaca a importância dos estudos pioneiros de Severo.

No rápido comentário que tece sobre as construções religiosas na conferência de 1914, Severo aponta que no Brasil dos primeiros tempos coloniais, o barroco teria desenvolvido uma característica original, daí

35 SEVERO, Ricardo. A Arte Tradicional no Brasil: a casa e o templo (1914), est. I e II. 36 SEVERO, Ricardo. A Arte Tradicional no Brasil: a casa e o templo (1914), est. III e IV. 37 SEVERO, Ricardo. A Arte Tradicional no Brasil: a casa e o templo (1914). p.64-66. 
a necessidade de qualifica-lo com o adjetivo jesuítico. Embora a "feição estética" desse "barroco jesuítico" nem sempre fosse "agradável, caindo facilmente em uma mesquinhez de proporções e pobreza de formas que tiram todo o interesse artístico de algumas construções religiosas da época", ${ }^{88}$ seriam óbvias as suas "íntimas ligações com Portugal" e o seu "cunho local digno de nota". ${ }^{39}$ Ligações que ele justificava não pelos argumentos já expostos, mas pelo fato de que teriam vindo da metrópole "os obreiros e muitos dos materiais para estas obras" ${ }^{40}$

Ainda em 1914, Severo ensaia a definição de uma tipologia religiosa, das igrejas mais simples, privilegiando os elementos e a composição da fachada principal. Este ensaio é aprofundado na conferência de 1916, quando o engenheiro apresenta cinco grupos arqueológicos ou tipologias religiosas, destacando alguns exemplos de ornamentação e arranjo espacial internos. Sua narrativa se inicia nos séculos XVII/XVIII com os exemplares mais simples, ditos "primitivos" até alcançar, no século XVIII, aqueles de maior complexidade e exuberância plástica. Nessa oportunidade, Severo recupera os argumentos já explicitados na conferência de 1914, elogiando os jesuítas, a ascendência portuguesa e a capacidade de adaptação dos modelos importados da metrópole no Brasil, o que teria gerado soluções originais como as materializadas nas igrejas de São Francisco de Assis de Ouro Preto e a do Carmo de São João del Rei. Para ele seria possível afirmar que "este tipo de plano curvilíneo é original nessa parte do Estado de Minas, como se fosse composição do mesmo arquiteto (o "Aleijadinho") da 2a metade do século XVIII". ${ }^{41}$ O elogio distinguiria Antônio Francisco Lisboa (1738-1814) de seus contemporâneos, construindo um lugar de exceção que seria

38 A reserva em relação à produção jesuítica parece ecoar as avaliações sobre ela produzidas na passagem do século XIX para o XX no horizonte de instituições como o IHGB e a Academia de Belas Artes do Rio de Janeiro, como mostra GOMES JÚNIOR, 1998. Contudo, apesar das críticas, Severo delas se distancia, porque, afinal, considerava de modo positivo a produção do barroco jesuítico pelas características acima expostas.

39 SEVERO, Ricardo. A Arte Tradicional no Brasil (1916). p.402.

40 SEVERO, Ricardo. A Arte Tradicional no Brasil: a casa e o templo (1914). p.74.

41 SEVERO, Ricardo. A Arte Tradicional no Brasil (1916). p.404. 
confirmado nos estudos subsequentes. Este lugar lhe seria garantido por seu talento e capacidade de amalgamar as referências portuguesas numa síntese própria, brasileira, atinente à necessidade de adaptação ao meio local. Na visada de Mário de Andrade, porém, a sua originalidade seria resultante da "mistura de civilizações, pela mestiçagem racial, cultural, estética (Peixoto, 2000, p.67). ${ }^{42} \mathrm{O}$ artífice era exemplo e pilar de sua "crença no valor da diversidade cultural brasileira que, reunida ou amalgamada, faria uma nova síntese" (Chuva, 2003, p.317), numa interpretação que o distanciava também das interpretações do grupo reunido ao redor de Rodrigo Mello Franco de Andrade no Sphan, mais preocupado em aproximar, como Severo, Aleijadinho da produção arquitetônica ocidental via Portugal.

Para a arquitetura religiosa, além da referência a Debret, Severo se apoia no livro do artista baiano Manuel Querino, Artistas baianos - indicações biográficas (1911). Devem ter contribuído para as suas análises também o material iconográfico que ele vinha coletando em suas pesquisas - basicamente composto de desenhos e fotos - e/ou adquirido por meio de encomendas feitas desde o seu estabelecimento definitivo no Brasil aos artistas Alfredo Norfini (1867-1944), Felizberto Ranzini (1881-1976) e José Wasth Rodrigues (1891-1957) (Mello, 2007; Kessel, 2008; Pinheiro, 2011).

Além dos aspectos já destacados em sua narrativa, chama atenção o fato de que as obras citadas pelo engenheiro se concentravam nos estados de São Paulo (7), Rio de Janeiro (7), Minas Gerais (4), Pernambuco (4) e Bahia (3). Se a proeminência de São Paulo é decorrente do engajamento de Severo com o projeto paulista de dominação político-cultural - compartilhado com o grupo social no qual estava inserido e que gravitava em torno do IHGSP, da Sociedade de Cultura Artística, d'O Estado de S. Paulo e da Revista do Brasil (Schwarcz, 1993; Chiarelli, 1995; Luca, 1999;

42 Em nota Fernanda Peixoto lembra ainda que em "1936, Gilberto Freyre dedica alguns parágrafos de seu Sobrados e Mucambos ao Aleijadinho, fazendo observações inspiradas em Mário de Andrade, como ele próprio reconhece. O sentido brasileiro e plural da obra do artista é sublinhado por Freyre, que destaca também, só que em outros termos, a mesma originalidade da invenção mulata afirmada por Mário e depois Roger Bastide" (PEIXOTO, 2000, p.67). 
Mello, 2007) - , é certo que os demais estados aparecem de modo recorrente a partir dos anos 1930 na historiografia e nas ações patrimoniais como se o que ali se ergueu representasse (Chartier, 1990) a totalidade da arquitetura brasileira (Gonçalves, 1996; Chuva, 2009).

Este seria o quadro geral da arquitetura tradicional que, segundo Severo, teria imperado, com relativa estabilidade entre os séculos XVII e XVIII, com o barroco dominando a cena arquitetônica local. Este quadro só seria perturbado do ponto de vista do engenheiro pela vinda da corte de D. João VI, em 1808. A mudança não teria tido grandes consequências uma vez que o neoclassicismo da missão francesa e da escola por ela fundada, a Academia Imperial de Belas Artes, não teria encontrado, tal como ocorrera em Portugal, "eco no sentimento popular, nem podia acomodar-se ao meio físico e social da época, devido à imperturbável rigidez dos seus moldes clássicos". Severo continua afirmando - divergindo de Taunay — que

essa tradição de matriz francesa não constitui aqui uma escola; ensinou porém e propagou a gramática da arte, a técnica perfeita do desenho, e criou uma academia de artistas que foi o laço entre o meio colonial e a orientação da renascença artística do século XIX. Nenhum dos discípulos, porém, reproduziu rigorosamente os modelos desse ativismo grego-romano [sic]; o meio tradicional emoldurou-os na sua influência absorvente, e foram persistindo os tipos coloniais do barroco até a independência da nação brasileira. ${ }^{43}$

A cena se alteraria a partir da independência do Brasil, quando o que considerava um "delírio emancipatório", teria levado o povo brasileiro a negar a arquitetura tradicional em prol de estilos importados de outros países que não se ajustavam nem ao meio telúrico local nem às raízes étnicas que lhes deram origem. O espírito imitativo adentraria à segunda metade do século XIX, período que teria sido "para as artes a idade da moda e dos 'pastiches"', cujo efeito seria "verdadeiramente

43 SEVERO, Ricardo. A Arte Tradicional no Brasil (1916). p.413. 
desastroso, é o postiço, a mentira, vazados de formas de construção definitiva e duradoura". ${ }^{4}$

A outra face desse processo seria a destruição das cidades e edificações coloniais, impulsionado aos olhos do engenheiro, de um lado por um "fenômeno natural em um país no seu período de desenvolvimento, que tem pressa de atingir a meta da civilização e do progresso", de outro, em função do "mau-gosto do proprietário e do mestre-de-obras" 45 que se deixavam seduzir por manifestações estranhas à nação, consideradas à época mais modernas. ${ }^{46} \mathrm{~A}$ perda seria ainda maior do que a mera disputa de estilos, na medida em que a arquitetura deixaria de ser o suporte do discurso e do sentimento nacionalista defendido pelo engenheiro como essenciais para amalgamar e fortalecer a nação e, assim, evitar o que ele qualificava como "o efeito dispersivo e desnacionalizante do moderno e utilitário cosmopolitismo". ${ }^{47}$ Sua Campanha de Arte Tradicional no Brasil procurava evitar esse efeito, recuperando por meio da história o fio da meada perdido desde a independência no Brasil para produzir uma arquitetura moderna, porém autêntica, expressão coletiva da nacionalidade pátria. Com esse intuito, Severo traça uma cronologia bastante interessada que inaugura uma explicação recorrente sobre a produção arquitetônica brasileira e a nação que a sustentava. Para tanto, Severo estabelece quatro períodos bem marcados: o primeiro, denominado "Brasil-Colônia", ia do descobrimento, mas sobretudo do século XVII com o início efetivo da colonização até a primeira a virada do século XVIII para o XIX, quando uma arte verdadeiramente tradicional tinha florescido; o segundo, nomeado "Brasil-Monarquia", teria se inaugurado no início do século XIX, com o primeiro momento de transformação e depois de "degenerescência" da arquitetura tradicional

44 SEVERO, Ricardo. A Arte Tradicional no Brasil: a casa e o templo (1914). p.79.

45 Se Lucio Costa também condena em "Documentação necessária” o mau gosto do proprietário, concordando com Severo, ele resguarda das críticas os mestres de obras, os quais seriam responsáveis, "sozinhos" por guardarem a "boa tradição" (COSTA, Lucio. Lúcio Costa: sobre arquitetura, p.94).

46 SEVERO, Ricardo. A Arte Tradicional no Brasil (1916). p.415-416.

47 SEVERO, Ricardo. A Arte Tradicional no Brasil (1916). p.417. 
em função do advento da Missão Francesa, da fundação da Academia de Belas Artes, mas principalmente do "triunfo da independência"; o terceiro período, denominado "Brasil-República, se iniciaria no últimos decênios do século XIX, quando a "ferida aberta pela independência" no curso "natural" de nossa tradição se aprofundaria, com a recusa a tudo que "lembrasse a velha metrópole ou os tempos ominosos [sic] da colônia" e a perda total de seu cunho nacional; o último período tomava corpo na década de 1910 com a sua campanha por meio da qual os laços tradicionais bruscamente perdidos no final do século XIX seriam recuperados, acertando o curso da história.

Em linhas gerais, a cronologia tecida por Severo é seguida por Marianno Filho, Mário de Andrade, Lucio Costa, Paulo Santos e Rodrigo Melo Franco de Andrade na valorização da arquitetura colonial produzida entre os séculos XVII e XVIII e na condenação da arquitetura do século XIX, sobretudo o ecletismo, pelo seu caráter estrangeiro. Mas para os três últimos autores, o momento de redenção da arte tradicional não se daria com o neocolonial e sim com o moderno, entre outros motivos pelo fato do neocolonial divisar com o ecletismo preceitos arquitetônicos historicistas de cunho tipológico-estilístico contra os quais eles se colocavam. De todo modo, mais uma vez a despeito das diferenças, em todos eles é claro o esforço de construir uma cronologia que repetisse "as fases de periodização da Europa civilizada", de modo a forjar "uma ancestralidade e uma herança, que permitiriam à nação [brasileira] prosseguir acompanhando, sincronicamente, a partir de então, a evolução da 'arte universal" (Chuva, 2003, p.325-326).

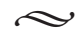

Ao recuperar neste artigo a narrativa de Ricardo Severo, além de apresentar seus preceitos e buscar as matrizes que embasaram o seu discurso acerca da arquitetura brasileira, procurei iluminar as semelhanças entre ele e as explicações que outros nomes da historiografia nacional teceram sobre o tema no campo da arquitetura, ainda que com divergências, indicando uma aproximação nem sempre notada pela historiografia. De fato, 
sabe-se que as conferências de Severo alcançaram grande repercussão a partir da década de 1920. Esta importância é normalmente creditada a um conjunto de fatores: a divulgação dessas conferências em instituições de grande prestígio e influência; o momento de sua formulação e publicização; o fato de que Severo desenvolveu, senão a primeira, a mais contundente narrativa global da história da arquitetura brasileira (Amaral, 1998; Chiarelli, 1995; Gomes Júnior, 1998; Luca, 1999; Mello, 2007; Kessel, 2008; Pinheiro, 2011). Se esses fatores contribuíram para a sua importância, eles não parecem dar conta de explicar a sua aderência por agentes tão diversos e mesmo conflitantes. Desse ponto de vista, mais do que as contingências de produção, circulação e consumo, a receptividade de sua campanha foi alcançada em grande medida porque parte significativa de seus propósitos, pressupostos e argumentos eram compartilhados por esses intelectuais e arquitetos. Assim, a despeito das diferenças que pesavam, sobretudo em função do elogio à mestiçagem e aos preceitos histórico-modernistas, o fato é que neocoloniais e modernos se aproximavam em uma construção historiográfica e do patrimônio da qual se destacam a retórica da perda, o elogio à autenticidade, o compromisso nacionalista, o ideal civilizador iluminista, o anseio por progresso, os parâmetros raciais e mesológicos, a crença na totalidade e unidade da nação, sintetizados todos em uma cronologia regida pelo elogio ao período colonial, em especial ao barroco, em detrimento do ecletismo.

Atentar para essa proximidade faz pensar em como a trama da historiografia da arquitetura brasileira (Martins, 1987; Cavalcanti, 2006) foi tecida com fios forjados ainda nos primeiros decênios do século XX, por figuras proeminentes como Ricardo Severo, apesar do confronto que se estabeleceu - e que foi endossado pela historiografia - entre os neocoloniais e modernos. Faz refletir sobre a importância de qualificar melhor tanto as semelhanças, quanto as diferenças, para evitar o perigo de interpretações anacrônicas. Faz, por fim, reconhecer que, apesar do interesse e da importância das proposições modernas, sobretudo no campo da arquitetura, há certos aspectos de seu discurso e atuação que falam muito sobre o conservadorismo excludente do projeto modernizador brasileiro, sobre o qual, e cada vez mais, há ainda que se investigar. 


\section{Agradecimentos}

A pesquisa da qual este artigo se origina teve início na dissertação de mestrado defendida em 2005, sob a orientação de José Tavares Correia de Lira, e publicada pela Annablume, com apoio da Fapesp, sob o título Ricardo Severo: da arqueologia portuguesa à arquitetura brasileira (2007). Uma primeira versão reduzida deste artigo foi apresentada no Simpósio Temático "Historiografia da arquitetura I: métodos, objetos e narrativas", organizado por José Lira e Margareth da Silva Pereira para o I Encontro Nacional da Associação Nacional de Pesquisa e Pós-graduação em Arquitetura e Urbanismo (2010). Agradeço a João Massao Kamita pelas sugestões feitas na ocasião, as quais animaram a sua revisão e ampliação tantos anos depois.

\section{REFERÊNCIAS BIBLIOGRÁFICAS}

Al ASSAL, Marianna Ramos Boghosian. Arenas nem tão pacíficas: arquitetura e projetos políticos em Exposições Universais de finais da década de 1930. Tese (Doutorado em História e Fundamentos da Arquitetura e do Urbanismo) - Universidade de São Paulo. São Paulo, 2014.

AMARAL, Aracy (org.). Arquitectura Neocolonial: América Latina, Caribe, Estados Unidos. São Paulo: Memorial Fondo de Cultura Económica, 1994. AMARAL, Aracy. Artes Plásticas na Semana de 22. São Paulo: Editora 34, 1998. ATIQUE, Fernando. Arquitetando a boa vizinhança: arquitetura, cidade e cultura nas relações Brasil-Estados Unidos (1876-1945). São Paulo: Pondes Editora/Fapesp, 2010.

AZEVEDO, Ricardo Marques de. Antigos e modernos: estudos das doutrinas arquitetônicas nos séculos XVII e XVIII. São Paulo: FAUUSP, 2009.

BACKHEUSER, Luiz Alberto Fresl. A casa do Arqueólogo. Contribuição ao estudo da obra de Ricardo Severo. Dissertação (Mestrado em Metodologias de Intervenção no Patrimônio Arquitetónico) - Universidade do Porto. Porto, 2006.

BANHAM, Reyner. Teoria e projeto na primeira era da máquina. São Paulo: Editora Perspectiva, 1975. 
BARROS, José D’ Assunção. Teoria da história. Petrópolis: Vozes, 2014.

BERMAN, Marshall. Tudo o que é sólido desmancha no ar. São Paulo: Companhia das Letras, 1986.

CAVALCANTI, Lauro. Moderno e brasileiro: a história de uma nova linguagem na arquitetura, (1930-1960). Rio de Janeiro: Jorge Zahar Editora, 2006.

CHAFEE, Richard. The Teaching of Architecture at École des Beaux-Arts. In: DREXLER, Arthur (ed.). The Architecture of École des Beaux-Arts. London: Scker\&Warburg, 1977. p.61-110.

CHARTIER, Roger. A história cultural, entre práticas e representações. São Paulo: Difel, 1990.

CHIARELLI, Tadeu. Um jeca nos vernissages: Monteiro Lobato e o desejo de uma arte nacional no Brasil. São Paulo: Edusp, 1995.

CHUVA, Márcia Regina Romeiro. Fundando a nação: a representação de um Brasil barroco, moderno e civilizado. Topoi, vol. 4, n. 7, p.313-333, jul-dez. 2003.

CHUVA, Márcia Regina Romeiro. Os arquitetos da memória: sociogênese das práticas de preservação do patrimônio cultural no Brasil (anos 1930-1940). Rio de Janeiro: Editora da UFRJ, 2009.

COLLINS, Peter. Los ideales de la arquitectura moderna: su evolución (1750-1950). Barcelona: Gustavo Gili, 1973.

COLQUHOUN, Alan. Três tipos de historicismo. In: NESBITT, Kate (org.). Uma nova agenda para a arquitetura: antologia teórica (1965-1995). São Paulo: Cosac Naify, 2006. p.221-232.

COMAS, Carlos Eduardo Dias. Protótipo e monumento, um mistério, o Ministério. In: GUERRA, Abílio (Org.). Textos fundamentais sobre história da arquitetura moderna brasileira: vol. 1. São Paulo: Romano Guerra, 2010a. p.79-108.

COMAS, Carlos Eduardo Dias. Teoria acadêmica, arquitetura moderna, corolário brasileiro. In: GUERRA, Abílio (Org.). Textos fundamentais sobre história da arquitetura moderna brasileira: vol. 2. São Paulo: Romano Guerra, 2010b. p.57-70.

COSTA, Angela Marques da; SCHWARCZ, Lilia Moritz. 1890-1914: no tempo das certezas. São Paulo: Companhia das Letras, 2000. 
FABRIS, Annateresa. Ecletismo na Arquitetura Brasileira. São Paulo, Nobel, 1987.

GOMES JÚNIOR, Guilherme Simões. Palavra Peregrina: o barroco e o pensamento sobre as artes e letras no Brasil. São Paulo: Edusp, 1998.

GONÇALVES, José Reginaldo Santos. Autenticidade, memória e ideologias nacionais: o problema dos patrimônios culturais. Estudos Históricos. Rio de Janeiro, vol. 1, n. 2, p.264-275, 1988.

GONÇALVES, José Reginaldo Santos. A retórica da perda: os discursos do patrimônio cultural no Brasil. Rio de Janeiro: Editora UFRJ: IPHAN, 1996. GUIMARÃES, Manoel Luis Salgado. Nação e civilização nos trópicos: o Instituto Histórico e Geográfico Brasileiro e o projeto de uma história nacional. Estudos Históricos. Rio de Janeiro, n. 1, p.5-27, 1988.

HOBSBAWM, Eric. A era dos impérios. São Paulo: Companhia das Letras, 1992.

HOBSBAWM, Eric. Introdução. A invenção das tradições. In: HOBSBAWM, Eric; RANGER, Terence. A invenção das tradições. Rio de Janeiro: Paz e Terra, 1997. p.9-23.

KESSEL, Carlos. Arquitetura neocolonial no Brasil: entre o pastiche e a modernidade. Rio de Janeiro: Jauá Editora, 2008.

LASSANCE, Guilherme. Ensino e teoria da arquitetura na França do século XIX: o debate sobre a legitimidade das referências. In: OLIVEIRA, Beatriz Santos de (et. Al.). Leituras em teoria da Arquitetura. vol. 1 Coleção PROARQ. Rio de Janeiro: Viana \& Mosley, 2009. p.92-112.

LE GOFF, Jacques. Documento/Monumento. In: História e Memória. Campinas: Editora UNICAMP, 2003. p.525-541.

LEMOS, Carlos Alberto Cerqueira. Ramos de Azevedo e seu Escritório. São Paulo: Pini, 1993.

LIRA, José Tavares Correia de. Mocambo e Cidade. Regionalismo na arquitetura e ordenação do espaço habitado. Tese (Doutorado em Arquitetura e Urbanismo) - Universidade de São Paulo. São Paulo, 1996.

LUCA, Tânia Regina de. A Revista do Brasil: um diagnóstico para a (N) ação. São Paulo: Fundação Editora da UNESP, 1999. 
MARINS, Paulo César Garcez. Através da rótula: sociedade e arquitetura urbana no Brasil, séculos XVII a XX. São Paulo: Humanitas/FFLCH/ USP, 2001.

MARTINS, Carlos A. F. Arquitetura e Estado no Brasil: elementos para uma investigação sobre a constituição do discurso moderno no Brasil. A obra de Lucio Costa (1924-1952). Dissertação (Mestrado em História) - Universidade de São Paulo. São Paulo, 1987.

MARTINS, Carlos A. F. Le Corbusier e Lúcio Costa: Afinidades Eletivas. In: NOBRE, Ana Luiza; KAMITA, João Masao; LEONÍDIO, Otavio; CONDURU, Roberto. (Org.). Lúcio Costa. Um modo de ser moderno. São Paulo: Cosac \& Naify, 2004. p.71-83.

MARTINS, Carlos A. F. Identidade nacional e Estado no projeto modernista. Modernidade, Estado e tradição. In: GUERRA, Abílio (Org.). Textos fundamentais sobre a história da arquitetura moderna brasileira. v. 1. São Paulo: Romano Guerra, 2010. p.279-97.

MELLO, Joana. Ricardo Severo: da arqueologia portuguesa à arquitetura brasileira. São Paulo: Annablume: Fapesp, 2007.

MENEGUELLO, Cristina. Da ruína ao edifício: neogótico, reinterpretação e preservação do passado na Inglaterra vitoriana. São Paulo: Annablume: Fapesp, 2008.

PATETTA, Luciano. Los revivals em arquitectura. In: ARGAN, Giulio Carlo [et. Al]. El pasado en el presente. El revival em las artes plásticas, la arquitectura, el cine y el teatro. Barcelona: Gustavo Gili, 1977.

PATETTA, Luciano. Considerações sobre o Ecletismo na Europa. In: Fabris, Annateresa. Ecletismo na Arquitetura Brasileira. São Paulo, Nobel, 1987. p.8-27.

PEIXOTO, Fernanda Arêas. Diálogos brasileiros: uma análise da obra de Roger Bastide. São Paulo: Edusp, 2000.

PEREIRA, Paulo. A arquitetura (1250-1450). In: PEREIRA, Paulo (org.). História da arte portuguesa, vol. I. Lisboa: Temas e Debates, 3ª Ed., 1999. PINHEIRO, Maria Lucia Bressan. Neocolonial, modernismo e preservação do patrimônio no debate cultural dos anos 1920 no Brasil. São Paulo: EDUSP - Editora da Universidade de São Paulo, 2011. 
ROCHA-PEIXOTO, Gustavo. A estratégia da aranha. Rio de Janeiro: Rio Book's, 2013.

ROWALD, Robert. Portugueses no Brasil independente: processos e representações. Oceanos. Lisboa, n. 44, p.8-21, out/dez 2000.

RUBINO, Silvana. Gilberto Freyre e Lúcio Costa ou a boa tradição. O patrimônio intelectual do Sphan. In: GUERRA, Abílio (Org.). Textos fundamentais sobre a história da arquitetura moderna brasileira. v. 1. São Paulo: Romano Guerra, 2010. p.299-310.

SCHWARCZ, Lilia Moritz. O Espetáculo das Raças: cientistas, instituições e questão racial no Brasil 1870-1930. São Paulo: Companhia das Letras, 1993. SILVA, Joana Mello de Carvalho; CASTRO, Ana Claudia Veiga de. Inventar o passado, construir o futuro: São Paulo entre nacionalismos e cosmopolitismos nas primeiras décadas do século 20. Pós. Revista do Programa de Pós-Graduação em Arquitetura e Urbanismo da FAUUSP, v. 21, p. 24-53, 2015.

SILVA, Joana Mello de Carvalho. O passado colonial em disputa: arquitetura luso-brasileira. Um debate entre Ricardo Severo e Mário de Andrade. Anais do VI Colóquio Luso-Brasileiro de História da Arte. v. 1. Rio de Janeiro: CBHA/ PUC-Rio/ UERJ/ UFRJ, 2004. p.331-344.

SILVA, Valeria Piccoli Gabriel da. "A pátria de minhas saudades": o Brasil na Viagem pitoresca e histórica de Debret. Dissertação (Mestrado em Arquitetura e Urbanismo) - Universidade de São Paulo, São Paulo, 2001. 